\title{
NICANOR PARRA, LA REVOLUCIÓN PERMANENTE
}

\section{Patricio Pron}

\begin{abstract}
No importa cuánto se hayan esforzado las vanguardias históricas por echar por tierra las formas artísticas establecidas, la poesía todavía se entiende como un consumo suntuario y prescindible, y en oposición a la prosa, que sería el lenguaje de los intercambios necesarios para la subsistencia. Este artículo argumenta cómo el trabajo de Parra, al cuestionar esta convención, posee un carácter inevitablemente político y marcadamente revolucionario.
\end{abstract}

No matter how much the historical avant-garde have strived to demolish established art forms, poetry is still understood as a dispensable and luxury consumption, unlike prose, which is supposedly the language of the interchange necessary for subsistence. This article argues that the work of Parra, questioning this convention, has an inevitably political and, more importantly, revolutionary nature.

Patricio Pron (Rosario, 1975). Escritor argentino. Autor, entre otros libros, de los volúmenes de relatos Hombres infames (1999), El vuelo magnifico de la noche (2001), El mundo sin las personas que lo afean y lo arruinan (2010) y La vida interior de las plantas de interior (2013), así como de las novelas Formas de morir (1998), Nadadores muertos (2001), Una puta mierda (2007), El comienzo de la primavera (2008) y El espíritu de mis padres sigue subiendo en la lluvia (2011). Sus últimas obras publicadas son la novela Nosotros caminamos en sueños y el ensayo El libro tachado, ambos en 2014. Email: patriciopron@gmail.com 
ean-Baptiste Poquelin, también conocido como Molière, o "el desafortunado Molière", escribió, famosamente, que todo lo que no es prosa es poesía y que, por consiguiente, todo lo que no es poesía es prosa. Algo más de un siglo después del comienzo de lo que es denominado el período de "las vanguardias históricas", y a pesar de los esfuerzos realizados por éstas para cuestionar las convenciones no sólo literarias de su época, la de Molière es la forma en que todavía suelen ser vistas estas cosas por ciertos lectores, que siguen pensando en la poesía en los términos en los que lo hacía el autor de El burgués gentilhombre: para ellos, poesía es todo aquello que no es prosa; es decir, todo lo que, a diferencia de la prosa, es intenso y elevado, retórico y lírico, "poético" en el sentido más penoso del término, de difícil comprensión (de la poesía de John Donne, por ejemplo, el rey Jacobo I de Inglaterra dijo que era "como el Reino de Dios: está más allá del entendimiento"1) y dotado de una trascendencia que la prosa, el modo en que nos comunicamos habitualmente, no tendría.

No parece necesario afirmar que ésta es una visión ingenua de la poesía, pero las consecuencias de esa visión merecen ser consideradas con algo más que con la indulgencia con la que hacemos frente a las manifestaciones de ingenuidad, puesto que, al concebir la poesía como algo distinto de la prosa que preside nuestros intercambios cotidianos (M. Jourdian afirma con asombro, en la pieza de Molière: “¡Dios santo! He estado hablando en prosa durante cuarenta años sin darme cuenta"2), al imaginar a la poesía como un lenguaje privado que se opondría al idioma público y de la colectividad, esta visión ingenua de la poesía ratifica la división entre aquellos que tienen una relación meramente funcional con el lenguaje y aquellos que podrían "recrearse" en él, entre aquellos que necesitan el idioma para comunicarse (sin que la comunicación constituya más que un medio en sí mismo) y aquellos que lo usan para crear, entre quienes producen y quienes añaden valor, entre los que sólo pueden hablar el lenguaje de los otros y aquellos que tienen

${ }^{1}$ Dennis Joseph Enright, ed., John Donne (Londres: Everyman, 1997), Introduction.

2 Molière, Le Bourgeois gentilhomme, http://www.toutmoliere.net/acte2,405364.html. 
un lenguaje "privado" (íntimo, suntuario) que serviría para su recreación y la de los que son de su clase, entre (al fin) la poesía y los que no podrían permitírsela, los pobres que sólo hablan en prosa.

Las convenciones literarias, todas ellas, son la manifestación en el ámbito de la literatura de convenciones y formas establecidas de origen económico y político (no me atrevo a decir que las convenciones literarias son su reflejo, aunque "reflejo" es una forma de expresar cómo funcionan en relación a lo consuetudinario en materia política y económica). No importa cuánto se hayan esforzado las vanguardias históricas por echar por tierra las formas artísticas establecidas (con la esperanza, a menudo, de que con ellas cayese también un cierto régimen político y económico), éstas permanecen en la visión de ciertos lectores ingenuos y depositan a la poesía del lado de lo supletorio, del consumo suntuario y no imprescindible, y en oposición a la prosa, que sería el lenguaje de los intercambios necesarios para la subsistencia; de allí que toda poesía que ponga en cuestión la convención que distribuye el uso de la poesía y de la prosa tenga un carácter inevitablemente político y, más aún, revolucionario. En ese sentido, en algún lugar de Chile el más radical de los poetas de la lengua española, Nicanor Parra, cumple cien años en este momento y su revolución no parece detenerse. A continuación, por qué.

\section{2}

No hay muchas virtudes que adornen a los escritores en sus comienzos, que suelen ser balbuceantes: el lector que yo fui en alguna ocasión también creyó saber cómo distinguir la poesía de la prosa. "En alguna ocasión" significa aquí, por supuesto, antes de leer a Parra. Por entonces yo era (lo he dicho ya, en otro lugar) un adolescente pobre en un barrio pobre de una ciudad pobre, en un país pobre cuya pobreza no era sólo material; o, mejor dicho, y en lo que se refiere específicamente a la poesía, era un país rico de una forma incomprensible y acaso fatal para quienes comenzábamos por entonces a leer poesía, puesto que la tradición poética argentina (esplendorosa, magnífica en algún sentido) era, al mismo tiempo, absolutamente impenetrable para nosotros, que todavía no habíamos recorrido el camino para acceder a ella, que pasaba por las vanguardias históricas, por la obra de Ezra Pound, por la 
de Wallace Stevens y la de T. S. Eliot. Naturalmente, ese camino podrá siempre ser llamado "via crucis" por algunos, pero en cualquier caso a nosotros (que no lo habíamos hecho) la poesía argentina nos resultaba un enigma indiferente, una especie de error que sólo podía ser reparado si se echaba la mirada al pasado y se escogían poetas "comprensibles", que corrigiesen con su obra a los poetas que eran sus sucesores. Nosotros escogíamos a Raúl González Tuñón antes que a Juan Gelman, a Nicolás Olivari por encima de Roberto Juarroz, a Leónidas Lamborghini antes que a María Negroni, a la poesía de Jorge Luis Borges por delante de la de Arturo Carrera. Éste no es un juicio de valor, excepto en relación a nuestras propias capacidades como lectores, que por entonces eran mínimas (las capacidades propias de lectores que comienzan a leer y que, por lo tanto, son susceptibles y presuntuosos e ingenuos), pero, aunque más tarde aparecerían en nuestras vidas de lectores los poetas argentinos que renovarían la escena que habíamos conocido (Martín Gambarotta, Juan Desiderio, Fabián Casas, Daniel Durand, Alejandro Rubio, Marina Mariasch, una decena de otros nombres), el arco que debíamos trazar, la inmersión en el pasado que nos correspondía realizar para encontrar un tipo de poesía que hablase nuestro idioma (o una variante de ese idioma, detenida en la jerga de nuestros padres e incluso en la de nuestros abuelos), que tuviese como tema el tipo de cosas que nos preocupaban por entonces, que estuviese anclada en algún tipo de experiencia que nos resultase comprensible, incluso teniendo que imaginarla en otra época, distinta a la nuestra, era enorme y agotador. No estoy empleando el plural mayestático aquí: realmente estoy hablando de lectores existentes, de aquellos que comenzamos a leer en torno a la primera mitad de la década de 1990 en Argentina y que conformamos involuntariamente algo parecido a una comunidad de intereses; la existencia de esa comunidad fue breve y terminó con la adopción de diferentes estrategias en relación con la poesía: algunos de sus integrantes leyeron y escucharon y trataron de comprender, y de ese modo adquirieron un conocimiento de la poesía argentina que es el de los conjurados, el de una minoría articulada como una sociedad secreta en el interior de la sociedad pública, con sus acaloramientos, con sus poses y con sus discusiones, incomprensibles para quienes no seguimos sus pasos; otros le dieron la espalda a la poesía argentina, convencidos de que la voz que hablaba allí lo hacía en una lengua muerta; por un raro azar (el 
de las publicaciones y el de la oferta de las librerías argentinas, siempre impredecible), algunos otros escogimos una forma distinta de tratar de comprender qué era la poesía y qué placer se podía extraer de ella y miramos hacia Chile, al otro lado de unas montañas que, en términos literarios, son más altas de lo que indican los libros de geografía. Y así fue que descubrimos a Parra. Y así fue que cambió todo para nosotros y la poesía nos ganó para su causa y nosotros ganamos a la poesía para las nuestras, cualesquiera que sean.

¿Qué vimos en Chile? Una poesía que estaba viva, que hablaba una lengua que entendíamos; parcialmente extranjera, pero, aun así, mucho más comprensible para nosotros (unos lectores que también pretendíamos estar vivos) que las lenguas muertas que parloteaban en la poesía argentina y que nosotros no sabíamos comprender.

\section{4}

El primer libro de Nicanor Parra que leí fue Poemas para combatir la calvicie. No recuerdo quién me lo prestó o de qué forma accedí a él, pero sí recuerdo que era un ejemplar que había sido utilizado, que estaba desvencijado en los sitios en los que aquellos libros que no provocan el interés o el entusiasmo nunca tienen daños. Naturalmente (y esto, supongo, señala ya una tendencia general), no comprendí mucho; es decir, no entendí (porque lo desconocía) cómo alguien podía tomarse esas libertades a la hora de escribir poesía, pero tuve la impresión de que esas libertades nos eran devueltas a los lectores que las habíamos perdido, por lo menos provisoriamente, buscando un sentido a la poesía argentina de la época. No sé qué piensan los demás, pero a mí la liberación que supone en el lector la lectura de Parra me ha parecido siempre una acción política. Tanto tiempo después, todavía recuerdo el entusiasmo y la sorpresa y la convicción de que estaba siendo ganado para la poesía por el humor y la vitalidad de un poeta del que yo no sabía absolutamente nada por entonces, y que, como todos los poetas que importan, me daba la impresión de estar hablándome sólo a mí, incluso aunque lo hiciera (y ésta era una novedad en mi vida de lector) en una lengua que 
era propiedad de todos, también de mí, de tal forma que el equivalente de esa lectura era una desinhibición política, como si Parra fuera un Movimiento de Liberación del Lector cuyas filas constasen de un solo miembro, aunque uno excepcional.

\section{5}

La política de liberación que propone la obra de Parra, pienso, se despliega en dos ámbitos: en el interior de la literatura y en su exterior, si es que éste existe. Los "antipoemas", por ejemplo, suponen el abandono de un paradigma anterior caracterizado por la frase de Molière. A diferencia del francés, Parra parece decir en una primera instancia que todo lo que es prosa es poesía; en una segunda instancia, con sus artefactos, completa el proyecto vanguardista de integrar vida y obra, viniendo a decir, no sólo que no existe distinción entre poesía y prosa, sino también que tampoco existe distinción alguna entre los textos y los objetos: ambas actitudes son parte de una tendencia general al cuestionamiento y a la posterior superación de los límites impuestos tradicionalmente a la producción poética en nombre de las instituciones literarias, lo que conecta a Parra con las vanguardias históricas y con su gesto violentamente desacralizador, cosa que ha llevado a Marlene Gottlieb a escribir que su poesía "es un ataque a las instituciones, tradiciones e ideologías políticas, religiosas y estéticas, mediante las cuales el hombre, 'danzarín al borde del abismo', se defiende del caos absurdo" 3 . Si (como digo) este gesto lo conecta con las vanguardias históricas, el humor de Parra le permite, sin embargo, llegar más lejos que éstas, ya que orienta su nihilismo no sólo contra las instituciones literarias, sino que también contra la autoridad que confieren al poeta quienes creen que éste es depositario de una "verdad trascendente". Las vanguardias históricas pretendieron reemplazar a unas autoridades por otras, pero Parra propone la supresión de la idea misma de autoridad, en un esfuerzo continuado de socavamiento de la figura del poeta mediante la ironía y el sarcasmo. Ante un poema como "Canción para correr el sombrero" ("iAy! Si yo les contara todos mis sufrimientos / imaginen el nieto de un Conde / pidiendo limosna en la vía pública: / ¡es para poner

${ }^{3}$ Citado por José García Nieto, en "Chistes par(r)a desorientar a la (policía) poesía", $A B C, 23$ de mayo, 1989, 50. 
los pelos de punta! // Además mi mujer se fue con otro / me dejó por un capitán de ejército / so pretexto de que soy paralítico / [...] / hay señoras mujeres en el siglo XX que se debieran desmayar de vergüenza") ${ }^{4}$, quienes conciban la poesía, en oposición a la prosa, como un cierto tipo de texto "elevado", "intenso" y "trascendente", sólo pueden manifestar su desconcierto.

Lo hizo, en 1962, el crítico literario y padre agustino Prudencio Salvatierra, quien se preguntó sobre Versos de salón lo siguiente: "¿Puede admitirse que se lance al público una obra como ésta, sin pies ni cabeza, que destila veneno y podredumbre, demencia y satanismo?"5. La respuesta, naturalmente, es que no, pero sólo si se acepta de forma acrítica el modo de comprender la poesía que Parra vino a poner en cuestión en la vida de todos nosotros y si se permanece aferrado al paradigma al que su obra puso fin cuando en "Manifiesto", un poema que fue publicado como cartel en 1963, declaró que "los poetas bajaron del Olimpo", agregando: "A diferencia de nuestros mayores / -Y esto lo digo con el mayor respeto- / Nosotros sostenemos / Que el poeta no es un alquimista. / El poeta es un hombre como todos / Un albañil que construye su muro"6.

\section{6}

"Durante medio siglo la poesía fue / el paraíso del tonto solemne"7, afirmó Parra en otro poema. La antipoesía del autor propone una vía para eludir la solemnidad que pasa por renunciar a la creación individual; si Parra no es un "tonto solemne" es debido a que ataca la idea de que un poeta pueda crear algo: de hecho, es notable cómo el chileno ha ido poco a poco dejando de ser poeta, en un sentido convencional, para convertirse en un recopilador o en un montajista, cuya actividad no consiste tanto en crear, sino en reunir materiales dispersos y heterogéneos que tengan la capacidad de significar al margen de su uso habitual y de

${ }^{4}$ Nicanor Parra, Parranda larga. Antología poética (Madrid: Alfaguara, 2010), 323-325.

${ }^{5}$ Citado por Niall Binns, en "Diccionario del antipoeta", El País, 21 de abril, 2012.

${ }^{6}$ Nicanor Parra, Obra gruesa (Santiago de Chile: Ediciones Universidad Diego Portales, 2012), 218-222.

7 “La montaña rusa", en Parra, Parranda larga, 115. 
la importancia que se les otorgue por lo común. De este modo, Parra evita caer en los excesos habituales de la trascendencia y de la banalidad (el poeta no puede ser ni una cosa ni otra porque, en sustancia, no está creando "nada" y no es "nada" en absoluto), pero también se coloca al margen de la crítica, puesto que el lector ya no puede considerar si lo que está leyendo es "buena" o "mala" poesía, porque los criterios con los que se la suele evaluar no son válidos para leer a Parra (quien, se puede decir, ni siquiera escribe "poesía": lo suyo, deliberadamente, es la "antipoesía").

En ese sentido, cabe la pregunta: ¿Hay antipoemas mejores que otros? Posiblemente sí, pero el establecimiento de una diferencia entre los buenos y los malos antipoemas dependerá siempre de la sensibilidad del lector, más que de un criterio académico o de cualquier norma no surgida de la obra misma de Parra. Esto es lo que hace tan difícil hablar de ella, y es posiblemente la razón por la que el Premio Cervantes que se le otorgó fue (para decirlo suavemente) tardío, y que los responsables del Premio Nobel se han decantado por poéticas más convencionales del español, en lugar de ceder a la evidencia de que el chileno es el poeta más importante de la lengua española de la última mitad del siglo XX.

Parra sólo se puede leer "desde" Parra, pero, al hacerlo, se accede a un territorio que es más amplio que el del poeta, ya que en él caben sus primeras influencias (Federico García Lorca y Walt Whitman), los escritores que conoce mejor (William Shakespeare, Franz Kafka, Aristófanes), los autores de la Beat Generation, W. H. Auden, Francisco de Quevedo y los surrealistas, así como toda una zona de la cultura popular chilena en la que se entreveran las cuecas (su libro La cueca larga es de una fecha tan temprana como 1958), los anuncios publicitarios, la retórica pública y, particularmente, el habla coloquial chilena, que Parra denomina "el idioma patrio"8.

\section{7}

Quienes alguna vez han intentado entrevistarlo afirman que el poeta se niega a que se lo grabe, en un gesto de coquetería (y no sólo de coquetería) que se propone como resistencia a la pérdida de las ha-

${ }^{8}$ Guillermo Pellegrino, "Con el poeta chileno Nicanor Parra: 'Debemos confiar en las variables ocultas"”, El País Cultural, 7 de julio, 2006. 
bilidades mnemotécnicas que están en el origen de la producción y circulación de poesía, y también, como una forma de evitar que el sentido aparente de lo que se dice acapare la atención del interlocutor acerca de "cómo" se dice, que para Parra es un problema fundamental. Como afirmó Antonio Skármeta, Parra "es un poeta 'oreja'. Sabe oír como nadie y, puesto que olvida como todos, lleva siempre lápiz y cuaderno y llena sus páginas con el bocadillo que luego les dará prestancia rústica a sus formulaciones más sofisticadas. [...] Nicanor triza los hablantes líricos de la poesía tradicional y moderna, los fragmenta, los despoja de su identidad unitaria, y hace a sus hablantes portadores de lo que se 'oye por allí', los transforma en redes conductoras de rumores, extravagancias, lugares comunes, y a veces purezas aún incontaminadas por el prestigio libresco"

La invención de la antipoesía (que Parra definió en 1958 como "el poema tradicional enriquecido con la savia surrealista" de lo que denominó el "surrealismo criollo"10) está vinculada con este interés por la vertiente más absurda de la literatura oral chilena y con el proceso de su acumulación, que hace posible el poema. En ese sentido, siempre he tenido la impresión de que en Parra no hay rastros del paternalismo tan frecuente en la poesía de tipo social con el que ésta, en especial en América Latina, ha querido "acercar la poesía al pueblo" imitando las formas del habla cotidiana. Parra nunca parece haber aspirado a ello, a este sueño recurrente de poetas progresistas y pesadilla habitual de lectores: en primer lugar, porque para el antipoeta chileno no existe una diferencia entre el poeta y el "pueblo"; en segundo lugar, porque (por consiguiente) no concibe que pueda haber una poesía que no pertenezca al "pueblo", que no sea el resultado de la acumulación y la disposición de unos materiales extraídos de un habla cotidiana que, en su naturaleza, incluye el sarcasmo, la ironía y el epigrama. Al igual que T. S. Eliot, Nicanor Parra se ha propuesto generar experiencias poéticas con "el lenguaje de la tribu", que en su caso es el lenguaje de Chillán, de lo que él llamó en alguna ocasión "el idioma de los barrios bravos de Chillán, el idioma patrio"11.

\footnotetext{
${ }^{9}$ Antonio Skármeta, "La lengua y la oreja", Revista Mercurio 140, abril de 2012.

${ }^{10}$ Citado en Álvaro Salvador, “¿Quién es Nicanor Parra?”, Revista Mercurio 140, abril de 2012.

${ }^{11}$ Pellegrino, "Con el poeta chileno...".
} 
En ese sentido, la antipoesía no es tanto un gesto de disidencia en relación con la poesía, sino más bien contra su retórica (que en la concepción de Parra habría alejado a la poesía de la experiencia poética y al lenguaje poético del idioma colectivo); es un despojamiento del artificio y su reemplazo, la ocupación del lugar vacío en la poesía, por una forma de oralidad que no es recreada, sino recuperada prácticamente sin intervención.

\section{8}

A lo largo de los años, la obra de Parra se ha convertido en testimonio de una manipulación cada vez menor de aquellos materiales que revelan su condición poética (decir que "se transforman en poesía" sería erróneo, o sólo sería acertado fuera del sistema de Parra) gracias a la intervención, a la curaduría, del autor. Pensemos en Temporal ${ }^{12}$, su último libro hasta la fecha.

\section{9}

La historia es conocida: Parra escribió Temporal en 1987, tras las inundaciones que afectaron a la zona central de Chile ese año, y a continuación perdió el manuscrito, que estuvo desaparecido durante más de dos décadas, hasta su recuperación gracias a un registro sonoro y su publicación por las Ediciones Universidad Diego Portales en 2014. Temporal constituye una oportunidad extraordinaria para asistir al momento en que el antipoeta articula un discurso crítico, una verdadera "poesía social" que se produce cuando abandona el centro de la escena y deja hablar a sus sujetos (el procedimiento, según Álvaro Salvador, es el de la "la yuxtaposición" y la "asociación libre e inconsciente de objetos pertenecientes a la realidad y distantes entre sí, en su materialidad o su sentido"13), cuyos discursos (como en la serie de los Trabajos prácticos y en los Artefactos) Parra manipula para convertirlos en experiencia poética (no en poesía: recordemos que ésta es la "antipoesía"), mediante lo que Alberto Madrid Letelier denominó (en su Gabinete de lectura: 2014).

12 Nicanor Parra, Temporal (Santiago: Ediciones Universidad Diego Portales,

13 Salvador, “¿Quién es Nicanor Parra?”. 
Poesía visual chilena) "diversas sintaxis y semánticas, que van desde el neodadaísmo, el ready-made duchampiano, el arte objetual surrealista, assemblages, la acumulación hasta los environment"14.

En Temporal irrumpen los anuncios televisivos y radiales ("URGENTEMENTE SE NECESITA / Sangre de cualquier tipo / Salve la vida de un damnificado / Falta ropa de cama / Sobran enfermos / Se necesitan almas generosas / Y muy en particular / Alimentos no perecibles / Hechos además de palabras"15), los comentarios de los afectados por la catástrofe ("No piensa ser catástrofe / Temporal desatado cuando mucho" "16), los noticiarios ("No sólo sufren los seres humanos / incluidos en ellos / los animales domésticos / Hasta las propias máquinas se quejan / Un teléfono por ejemplo / Declaró que pensaba suicidarse / Más noticias en cualquier momento"17), los grafitis ("Derrotaremos a la naturaleza / Tal como derrotamos al marxismo", "En mi modesta opinión / Este país no llega al año 2000"18), etcétera. El poeta se integra desde el comienzo a un "nosotros" hipotético, conjetural; se distancia de él mediante deícticos y el uso de la primera persona en algunos poemas ("Pero lo que yo quiero subrayar"19), pide y otorga la palabra ("Ofrezco la palabra // ¿Por qué los pobres diablos / No reciben un peso? / Todo desaparece en el camino // Los coroneles tienen la palabra / [...] Ofrezco la palabra // Los comunistas tienen la palabra / Los extremistas tienen la palabra / Sursum corda / Los degollados tienen la palabra"20), adopta la voz del río desbordado (“Algunos dicen que es / El indomable espíritu mapuche / Quien se expresa a través de mis actos / Esa es una soberana mentira / Yo no me identifico para nada / Con ninguno de los bandos en pugna / Soy un humilde estero nada más / Un arroyo pacífico / Turbio por fuera / pero cristalino por dentro"21; "A ESTAS ALTURAS YA DEBIERA SABERSE / Que conmigo no corren los semáforos / Arraso lisa y llanamente / Con lo que se me ponga por de-

${ }^{14}$ Alberto Madrid Letelier, Gabinete de lectura: Poesía visual chilena (Santiago de Chile: Ediciones Metales Pesados, 2006), 69-75.

15 Parra, Temporal, 15.

${ }^{16}$ Ibídem, 25.

${ }^{17}$ Ibídem, 35.

${ }^{18}$ Ibídem, 49.

${ }^{19}$ Ibídem, 53.

${ }^{20}$ Ibídem, 57-58.

${ }^{21}$ Ibídem, 29. 
lante / El alcalde está loco / No respeto los monumentos de mármol / Y voy a respetar esta basura"22) o se traviste en un "hablante lírico" ("EL HABLANTE LÍRICO DE ESTE POEMA / Recomienda comunicarse / Con el fantasma del Corregidor / Él es un entendido en la materia / Sus construcciones no se caen solas"23), pero, en última instancia, regresa a un "nosotros" que es un "CORO DE DAMNIFICADOS: / Nadie se preocupa de nosotros / A la tortura sórdida de la tierra / Se suma ahora la tortura del cielo // ¿Puro Chile es tu cielo azulado? / ¿Puras brisas te cruzan también? Y tu campo de flores bordado / ¿Es la copia feliz del edén?".

En su Manifiesto (1963), Parra había hecho explícita su voluntad de escribir una poesía social: "Contra la poesía de las nubes / Nosotros oponemos / La poesía de la tierra firme / (...) Contra la poesía de salón / La poesía de la plaza pública / La poesía de protesta social"24. Temporal es esa "poesía de la plaza pública", cuyas voces el autor reproduce para poner de manifiesto que la experiencia poética está entre los efectos que produce de forma natural el habla cotidiana. En algún sentido (y esto lo descubriría con el tiempo, cuando yo mismo me convirtiera en escritor), la obra del chileno es un correctivo contra las visiones excesivamente optimistas que los escritores solemos tener acerca de nosotros mismos y de nuestro trabajo porque supone un desplazamiento de la noción de valor en literatura, que pasa de la autoría individual (y del consenso acerca del talento del autor, poco o mucho) a la capacidad de la obra para reconstruir una comunidad capaz de producir actos poéticos por sí misma.

La antipoesía de Parra es, en ese sentido, una revolución permanente: se opone a todo lo que ésta había considerado históricamente su tarea y su principal valor, puesto que no propone una poesía cuya dimensión social radique en la dirección que ésta sigue (del sujeto individual a un hipotético colectivo de lectores, podríamos decir), sino una que vaya del sujeto colectivo al sujeto colectivo pasando por una

\footnotetext{
${ }^{22}$ Parra, Temporal, 41.

${ }^{23}$ Ibídem, 31.

${ }^{24}$ Parra, Parranda larga, 145-150.
} 
pequeña pero significativa intervención del poeta, más un gestor que un creador en el sentido habitual del término; parte de un "nosotros" que no necesita el tutelaje del artista para producir sentido: "NUESTROS MAYORES / Eran más instruidos que nosotros / Sabían cómo se debe solicitar una gracia / Golpeándose el pecho desde luego / Con humildad / Con fe / Con esperanza / Poco se gana con escupir para arriba"25.

La obra de Parra responde, pues, a la pregunta de cómo escribir poesía en Chile después de Pablo Neruda y de Vicente Huidobro. La literatura argentina, que presenta un problema similar con Borges y con Roberto Arlt, pone de manifiesto que la mejor forma de superar a una figura de esa importancia es no ignorarla ni imitarla, sino redefinir el marco en el que ésta se inscribe, de tal manera que ya no ocupe el lugar central sino uno periférico. Es lo que hizo Parra al apartarse de la visión de la poesía como producción individual y creativa para adherir a la idea de que la realización de experiencias poéticas es colectiva, está en los actos del habla cotidiana y debe regresar a ella tras la intervención del antipoeta, en una actividad necesariamente "no creativa". La pregunta que preside toda su obra es cómo crear una lengua poética que sea privada a la vez que pública; su respuesta es que el poeta no debe crear sino recolectar, reunir, mezclar, y es una respuesta inusualmente temprana: se encuentra en el origen del Quebrantahuesos, el periódico mural que Parra, Enrique Lihn y Alejandro Jodorowsky pegaban en las paredes de Santiago en 1952 y en el que el método antipoético de Parra ya estaba completamente desarrollado. ¿Qué nos dice el Quebrantahuesos acerca de Parra? Mejor aún, ¿qué nos dice del Nicanor Parra que todavía no ha publicado sus Poemas y antipoemas? Que prefiere la producción colectiva a la individual, que concibe la creación como una operación de repetición con distancia crítica, que no establece distinciones entre elementos de la "cultura alta" (el collage surrealista) y la "cultura baja" (la prensa periódica), que constituyen la forma en que, consuetudinariamente, aceptamos la existencia de la sociedad de clases y asignamos a cada una de ellas unas preferencias y unos hábitos hipotéticos.

${ }^{25}$ Parra, Temporal, 43. 
La política de la obra de Parra es, en ese sentido, libertaria; está dirigida al cuestionamiento de las limitaciones impuestas al sujeto por la sociedad, de allí que también opere en el ámbito exterior de la literatura como una invitación a vivir al margen de la forma en que se nos dice que debemos hacerlo. Parra propone la producción incesante de experiencias poéticas que refuercen al sujeto colectivo, permitiéndole, en palabras de Leónidas Morales, "elaborar y comunicar una visión de las implicaciones morales y culturales de la experiencia"26. En ese sentido, es particularmente interesante observar los pasajes de su obra en los que presenta al sujeto individual: en casi todos los casos se trata de un personaje acobardado, carente de heroicidad, sin una visión certera acerca de sí mismo y de la forma en que vive; un energúmeno. "Este personaje", sostiene Álvaro Salvador, "se salva de los abismos de la locura gracias a los recursos que le proporciona su mismo lenguaje, ese lenguaje elaborado según el modelo del lenguaje hablado de todos los días y en todos los lugares, reforzado por el especial sentido del humor que sus articulaciones gramaticales ponen en funcionamiento para evidenciar lo oculto, sembrar dudas sobre lo evidente o socavar los valores aparentemente más sólidos o inamovibles" 27 .

\section{2}

La revolución permanente de Nicanor Parra es una revuelta contra la idea del "genio creador"; contra la de la unidad de la obra artística; contra la de la finitud del proceso creativo (tachaduras, correcciones y enmiendas son parte de su producción última, lo que le otorga un carácter de "work in progress"); contra la de "cultura alta" y "baja"; contra las convenciones tipográficas; contra el consenso que en literatura significa la adhesión a un sistema estable de valores; contra la idea misma de un sistema estable; contra la idea de que el soporte literario es el papel y, su unidad, el libro (Parra puede recurrir a bandejas de confitería, trozos de madera, postales, periódicos, objetos cotidianos a los que otorga sentido mediante la yuxtaposición de textos); contra la pseudonimia, que constituye una variante de la separación de literatura y vida, en el sentido de que reemplaza al nombre cívico, real, por uno "literario"

\footnotetext{
${ }^{26}$ Citado en Salvador, “Quién es Nicanor Parra?”.

27 Salvador, “¿Quién es Nicanor Parra?”.
} 
(en ese sentido, Parra es uno de los primeros poetas chilenos que prescindieron del pseudónimo al que sí recurrieron Lucila Godoy Alcayaga, Carlos Díaz Loyola, Luisa Anabalón Sanderson, Moisés Gutiérrez, Gilberto Concha Riffo, Ricardo Eliecer Neftalí Reyes Basoalto y otros); contra la idea de que la poesía tiene que adoptar bandos (es famosa la frase: "la izquierda y la derecha unidas / jamás serán vencidas"28); contra la idea de la poesía como una propedéutica (¿qué podría enseñar el sujeto individual a un colectivo del que no se considera desmigajado?) o como testimonio (porque, ¿cómo podría testimoniar algo que no fuese conocido por ese colectivo, si él es parte de él y lo constituye?); contra los hábitos que presiden la lectura de poesía y la particular relación entre un poeta y su obra (la ironía y el humor son sus recursos para tener en permanente tensión al lector, que no sabe si se le habla "en serio" o "en broma"); contra la idea de que la poesía debe ser hermética o aludir a una realidad "interior" de difícil acceso (el tipo de poesía que estuvo a punto de derrotarme en Argentina, cuando era joven); contra la idea expresada por Theodor Adorno de que ya no se podría escribir poesía después de Auschwitz.

La antipoesía de Parra no se propone servir de consuelo respecto de las grandes tragedias del siglo XX: opera con ellas y constituye una instancia superadora, que pretende devolver la poesía al habla cotidiana y el sujeto al colectivo; es decir, recomponer todo aquello que los totalitarismos y los crímenes del siglo XX disolvieron y anularon. No es poesía, es una experiencia poética en sí misma. No está concebida para aliviar las cargas de la vida: es la vida, manifestándose. Si Raúl Zurita comenzó siendo para algunos de nosotros una nota a pie de página de la obra de Roberto Bolaño, otro poeta más del país de los poetas latinoamericanos por antonomasia (si acaso, el último de su diccionario biográfico), y Nicanor Parra una especie de oráculo irónico ubicado al otro lado de las montañas (yo escapé de casa y quise visitar Chile en 1992, a los dieciséis años: fui devuelto en la frontera por los carabineros, mandado en un autobús de regreso a la ciudad de Mendoza, decepcionado; acabo de recordarlo), con el tiempo terminamos comprendiendo que era más bien el país de los poetas el que servía de nota a pie de página de la obra de Parra, que lo supera en importancia y trascendencia. Entre

${ }^{28}$ Nicanor Parra, Voy \& vuelvo (Santiago de Chile: Ediciones Universidad Diego Portales, 2014), 54. 
los poetas chilenos contemporáneos se me ocurre que sólo de Zurita se puede decir lo mismo: que no es parte de la literatura de un país (cosa que, por lo demás, es de todas formas), sino que es (para sus lectores) ese país, con sus costas y sus precipicios. A ese país (vale la pena insistir) algunos le debemos todo; también le debemos pensar en la poesía, no como en un cementerio marino, sino como en un sitio donde la vida y sólo la vida son más importantes que el dolor y las tragedias de nuestro pasado. Eso, por supuesto, también es algo que aprendimos de Nicanor Parra, cuyos acentos están presentes, de forma sutil pero indisimulable, en la poesía y en cierta prosa argentinas; es decir, en la literatura de un país donde su figura (por fin) ya no es un secreto a voces. EP. 